\title{
Black Soldier Fly Hermetia illucens as a Novel Source of Chitin and Chitosan
}

\section{Adelya Khayrova ${ }^{1,2}$, Sergey Lopatin ${ }^{1}$, Valery Varlamov ${ }^{1}$}

\author{
${ }^{1}$ The laboratory of biopolymer engineering, Institute of Bioengineering, Research Center of Biotechnology of the \\ Russian Academy of Sciences, Moscow, Russia \\ ${ }^{2}$ Entoprotech LLC, Moscow, Russia
}

\begin{abstract}
Black soldier fly allows to efficiently convert residual biomasses into a valuable source of biomolecules, such as proteins, lipids and chitin. In this study, a new method for obtaining amorphous chitin from the black soldier fly larvae was developed with a further deacetylation step. Amorphous chitin was obtained by direct extraction using concentrated phosphoric acid. The purity of the resulting chitin was confirmed by physicochemical methods (elemental analysis, IR spectroscopy, measurement of primary amines, amino acid analysis). Crystalline chitin and high molecular weight chitosan were obtained by the standard procedure including demineralisation, deproteinisation and deacetylation steps. This method allows to extract chitosan, suitable for a wide range of applications.
\end{abstract}

Keywords: Chitin, Chitosan, Hydrolysis, Deacetylation, Insects, Black Soldier Fly, Hermetia Illucens

\begin{abstract}
Introduction
Chitin is the second most abundant polysaccharide on earth after cellulose. Chitosan is a common derivative of chitin produced by deacetylation reaction. Due to its exceptional biological and chemical qualities, chitosan has drawn broad attention to the worldwide research projects and can be used in many industrial and biomedical applications ranging from drug delivery and cosmetics to food processing and agriculture (H. E. Knidri et al., 2018).
\end{abstract}

Chitin consists of ordered crystalline microfibrils, forming structural components in the exoskeleton of arthropods or in the cell walls of fungi and yeast (A. Younes et al., 2015). The most common industrial sources of chitin are crustaceans, crab and shrimp shells. Its industrial production process involves the removal of calcium carbonates and proteins by demineralisation and deproteinisation steps, respectively. In addition, decolourisation and purification steps are often required to obtain a pure product without pigments or impurities (Y.S. Puvvada et al., 2012). In recent years, the emphasis on environmentally friendly technology resulted in increased attention in biopolymers due to their improved functionality and biodegradability compared to synthetic polymers (F. Croisier et al., 2013; S. Kumari et al., 2014). Since the range of chitin and chitosan applications is expanding, new biopolymer sources are developing. Insects serve as a potential source of these biopolymers (M. Kaya et al., 2015; M. Kaya et al., 2016; C.Y. Soon et al., 2018; Q. Luo et al., 2019). It is known that chitin makes up to $50 \%$ of insect exoskeleton.

\begin{abstract}
Nowadays, the novel technology of black soldier fly (Hermetia illucens) rearing is becoming increasingly popular around the world. It embraces the concept of circular economy by solving two global problems simultaneously: feed protein deficiency and organic waste utilisation. According to the Food and Agriculture Organisation of the United Nations (FAO), almost a third of all food produced (almost 1.6 billion tons per year) in the world is wasted. Several methods (e.g. waste disposal, incineration, composting) to reduce the amount of organic waste are known. However, black soldier fly treatment is considered to be more ecologically and economically viable. For instance, research results show that direct $\mathrm{CO}_{2}$ eq emissions from black soldier fly biowaste treatment are 47 times lower the emissions from composting (Mertenat et al., 2019). When processing Hermetia illucens at different stages of ontogenesis to several feed products, chitin-containing material is left as a by-product. Therefore, with development of the utilisation technology it would be possible to both increase the effectiveness of the rearing technology and obtain valuable biopolymers - chitin and chitosan.
\end{abstract}
Materials and Methods
Materials
Hermetia illucens larvae of the fifth instar were provided by Entoprotech LLC, Russia. $3000 \mathrm{~g}$ of larvae was blanched. The processed larvae went through the oilpress (RawMID, Russia) treatment to remove the majority of lipids, proteins and moisture. Then the resultant larvae were lyophilised and kept in air-tight plastic seal. The product contained 
approximately $6 \%$ of lipids and $7 \%$ of ash. $250 \mathrm{~g}$ of product was obtained (yield $=8 \%$ ).

\section{Crystalline chitin preparation}

Defatting: $500 \mathrm{~mL}$ of $\mathrm{CHCl}_{3}: \mathrm{CH}_{3} \mathrm{OH}$ (7:3) mixture was added to $100 \mathrm{~g}$ of larval shells. The suspension was stirred at $20^{\circ} \mathrm{C}$ for $4 \mathrm{~h}$. The shells were filtered through glass filter, washed with $50 \mathrm{~mL}$ of organic mixture and dried under vacuum. As a result, $93 \mathrm{~g}$ of chitin-containing material was obtained (yield=93\%). Demineralisation: $1000 \mathrm{~mL}$ of $2 \% \mathrm{HCl}$ was added to the obtained material and left at $20{ }^{\circ} \mathrm{C}$ for $2 \mathrm{~h}$. The solid residue was separated through glass filter. It was washed with distilled water and lyophilised afterwards. $23 \mathrm{~g}$ of product was obtained (yield=58\%).

Deproteinisation: $250 \mathrm{~mL}$ of $5 \%$ (w/w) $\mathrm{NaOH}$ was added to $20 \mathrm{~g}$ of demineralised biomass and left in 50 ${ }^{\circ} \mathrm{C}$ water bath for $2 \mathrm{~h}$ with occasional stirring. Chitin was separated through glass filter, washed with distilled water until neutral $\mathrm{pH}$ and lyophilised. $9.2 \mathrm{~g}$ of product was obtained (yield $=46 \%$ ).

\section{Chitosan preparation}

Deacetylation: the deacetylation step was performed by using $250 \mathrm{~mL}$ of $50 \%$ (w/w) $\mathrm{NaOH}$. The alkaline solution was added to $7.5 \mathrm{~g}$ of chitin and left at room temperature for $30 \mathrm{~min}$. The suspension was warmed in $100{ }^{\circ} \mathrm{C}$ water bath for $2 \mathrm{~h}$ with occasional stirring. The suspension was cooled, washed until neutral $\mathrm{pH}$ and lyophilised. $4 \mathrm{~g}$ of chitosan was obtained ( yield=53\%).

Purification: $4 \mathrm{~g}$ of chitosan was dissolved in $400 \mathrm{~mL}$ of $1 \% \mathrm{CH}_{3} \mathrm{COOH}$. The solution was filtered through glass filter. $1 \mathrm{M} \mathrm{NaOH}$ was then added until $\mathrm{pH} 10$ was achieved. The solution was dialised in Spectra/Por Dialysis Tubular Membrane MWCO: 10,000 (Spectrum Laboratories Inc., USA) to remove excess alkali and salts and lyophilised. $3.2 \mathrm{~g}$ of chitosan was obtained (yield $=80 \%$ ).

\section{Amorphous chitin preparation}

$25 \mathrm{~g}$ of larvae was mixed with $100 \mathrm{~mL}$ of $85 \% \mathrm{H}_{3} \mathrm{PO}_{4}$ solution and left at room temperature for $16 \mathrm{~h}$. The samples were filtered through glass filter and washed with $50 \mathrm{~mL}$ of $40 \% \mathrm{H}_{3} \mathrm{PO}_{4}$ solution. Dissolved chitin was reprecipitated by adding $2 \mathrm{~L}$ of distilled water while mixing thoroughly. The chitin was decanted and washed extensively with distilled water until neutral $\mathrm{pH}$ to remove excess alkali. Chitin samples were then lyophilised. As a result, $1.75 \mathrm{~g}$ of amorphous chitin was obtained (yield=7\%).

\section{Alkaline hydrolysis of amorphous chitin}

$15 \mathrm{~mL}$ of $50 \%$ (w/v) $\mathrm{NaOH}$ was added to $1 \mathrm{~g}$ of amorphous chitin isolate. The reaction mixture was heated in $100^{\circ} \mathrm{C}$ water bath for $1 \mathrm{~h}$ with occasional stirring. $60 \mathrm{~mL}$ of distilled water was added to the reaction mixture. The cation exchange resin
Amberlite IRC-50 (Sigma, USA) was used to remove the alkali. Spectra/Por Dialysis Tubular Membrane MWCO: 3,500 (Spectrum Laboratories Inc., USA) was used to dialise the solution (to remove the left alkali and low molecular weight components), and the product was lyophilised. $0.32 \mathrm{~g}$ of chitosan was obtained (yield=32\%).

\section{Characterisation \\ IR analysis}

The purity of amorphous chitin was confirmed by IR spectroscopy (Perkin-Elmer 1420, USA). The IR spectrum was recorded in the range of wavelength $400 \mathrm{~cm}^{-1}-4000 \mathrm{~cm}^{-1}$. The sample was prepared in $\mathrm{KBr}$.

\section{${ }^{1}$ H NMR analysis \\ ${ }^{1} \mathrm{H}$ NMR spectrum of chitosan was recorded on a Bruker AMX 400 spectrometer, USA (400 MHz) at $32{ }^{\circ} \mathrm{C}$. Samples were prepared in deuterated water. 4,4-dimethyl-4-silapentane-sulfonic acid was used as a standard. The solvent signal was suppressed by selective pulses using gradients. The degree of deacetylation (DD) was calculated according to the formulas (A. Hirai et al., 1991).}

\section{Measurement of free amino groups}

The procedure employed for the measurement of free primary amines by ninhydrin method is described by Taylor (1993).

\section{Molecular weight $\left(M_{w}\right)$ and polydispersity}

The weight-average $\left(\mathrm{M}_{\mathrm{w}}\right)$ and number-average $\left(\mathrm{M}_{\mathrm{n}}\right)$ molecular weights and polydispersity indices $\left(\mathrm{PI}=\mathrm{M}_{\mathrm{w}} / \mathrm{M}_{\mathrm{n}}\right)$ of chitosan samples were determined by High-Performance Liquid Chromatography (HPLC) (Sykam, Germany) by the method described by S.A. Lopatin et al. (2009). Monodispersed dextrans $\left(\mathrm{M}_{\mathrm{W}}\right.$ 1080, 4440, 9890, 43500, 66700, 123600, 196300, 276500 and $401300 \mathrm{kDa}$ ) (Sigma, USA) were used as calibration standards.

\section{Conductometric titration}

Conductometric titration was performed according to Lyalina et al. (2017). $0.1 \mathrm{~g}$ of chitosan was dried to a constant weight in a microwave oven. The chitosan sample was dissolved in $10 \mathrm{~mL}$ of $0.1 \mathrm{M} \mathrm{HCl}$ and then diluted with $40 \mathrm{~mL}$ of distilled water. $100 \mu \mathrm{L}$ of $0.1 \mathrm{M} \mathrm{NaOH}$ titrated solution was added to the chitosan solution, and the titration curve was plotted.

\section{Results and Discussion}

Black soldier fly can be used as a potential source of chitin and chitosan. However, unlike the traditional sources of these biopolymers (crustacean shells), this insect has a number of unique features. First, it contains a high amount of lipids, therefore, requiring defatting as a preliminary step. Secondly, the pigmentation can be seen in the later stages of ontogenesis due to melanin, covalently bound to chitin. Hence, it is impossible to separate such 
complex without the destruction of chitin. Therefore, to obtain chitin and chitosan, it is necessary to use non-pigmented raw materials, for example, the membranes of larvae of the fifth instar.

Chitosan production process follows the standard procedure including defatting, demineralisation, deproteinisation and deacetylation steps. However, obtained chitosan requires additional purification step by reprecipitation from a solution in acetic acid. It was noticed that in the area of the oral cavity of the larvae, chitin (and further chitosan) forms a complex with melanin, insoluble in organic and mineral acids. Presumably, the chitin-melanin complex is harder than pure chitin, which facilitates the process of food grinding by larvae. Nevertheless, the presence of pigmentation in the oral cavity of the larvae is observed from a very early age.

Approximately $20 \%$ of matter is removed when chitisan is redissolved, which indicates its high purity. Without any further purification such chitosan can be used, for instance, to remove heavy metal ions. Obtained chitosan was characterised by HPLC method. Chitosan had $\mathrm{M}_{\mathrm{w}}$ of $160 \mathrm{kDa}$ and PI of to 1.5. DD was calculated based on the conductometric titration and ${ }^{1} \mathrm{H}$ NMR (Figure 1) spectroscopy. DD was the same for both methods and equal to $90 \%$.

The processes of obtaining chitin from Hermetia illucens larvae described in the literature (Wasko et al., 2016; Caligiana et al., 2018) aim to sequentially remove the impurities from the chitin-containing raw material. However, this approach consists of multiple steps and does not result in a pure product. In order to overcome these issues, the method of direct extraction to obtain chitin from H. illucens larvae was developed. It is known that chitin is soluble in concentrated mineral acids, such as hydrochloric, sulfuric, phosphoric, etc. However, this property has not been previously applied to obtain chitin. Phosphoric acid was used as it does not hydrolyse chitin during its extraction process (unlike hydrochloric and sulfuric acids). The proposed method (Patent No. 2680691) for producing chitin does not require defatting, demineralisation or deproteinisation steps, which are carried out by treating the raw material with organic solvents or an alkali solution at high temperatures. The remaining larval material can be used as a feed additive after being washed or neutralised with phosphoric acid, while neutralised phosphoric acid - as a fertiliser.

It was found that the content of free amino groups in the obtained chitin is $4.0 \%$, which is consistent with the corresponding values of chitin isolated from crab (Bioprogress LLC, Russia) and shrimp (Sigma, USA) shells. Therefore, the residues of phosphoric acid would be counterions for these amino groups.

The elemental analysis data of chitin, including $\mathrm{C}, \mathrm{N}$, $\mathrm{P}$ and $\mathrm{H}$, are shown in Table 1 . The experimental values differ from the theoretical ones. However, it is known that biopolymers contain $10-12 \%$ of bound water. Therefore, if this property is taken into account, the experimental results become consistent with the theoretical values. The ash content was equal to $3 \%$. The protein content was determined using amino acid analysis $-4.3 \%$. However, if chitin is extracted from the demineralised material, the protein content drops to $1.0 \%$, while the ash - to $0.2 \%$.

In addition, the resulting chitin is amorphous rather than crystalline. Therefore, its colloidal solution can be used as a substrate for determining the chitinase activity of enzymes. Its application in the study of the activity of recombinant enzymes such as chitinases and chitosanases was demonstrated previously (A.S. Khayrova et al., 2018) and its advantage compared to a substrate based on crab chitin was shown.

IR analysis was performed to confirm the purity of amorphous chitin. Figure 2 shows two spectra that were taken to compare the product with the reprecipitated crab chitin, which was used as a reference. The IR spectra are almost identical, which confirms the high purity of the end product.

It should be noted that when using untreated larvae, both blanched and dried, no extraction of chitin occurs. This can be explained by the high fat content in the larvae, preventing the interaction of phosphoric acid with the cell walls due to the hydrophobic repulsion. In addition, the possibility of extracting chitin with phosphoric acid from pupae and dead insects was studied. It was shown that chitin cannot be extracted from such highly pigmented raw materials. This is due to the fact that chitin is strongly bound to melanin in pupae and dead insects, thus, such complex is insoluble in acids.

Chitosan is obtained through deacetylation reaction which involves the removal of the acetyl groups from the chitin molecule. Since the structure is amorphous, chitin contains acetyl groups less sterically hindered than in crystalline chitin, it was assumed that these functional groups can be removed under milder conditions. Chitin was treated with 10, 20, 30, 40 and $50 \%(\mathrm{w} / \mathrm{v}) \mathrm{NaOH}$ solution at $100^{\circ} \mathrm{C}$ for $1 \mathrm{~h}$. The samples were then filtered through glass filter, washed with water and dried. It turned out that in the first four cases, the obtained substances did not dissolve in $1 \%$ acetic acid, indicating that the deacetylation reaction did not go to completion.

When treated with $50 \%(\mathrm{w} / \mathrm{v}) \mathrm{NaOH}$ solution, the resulting substance was dissolved when washed with water. This suggests that the resulting chitosan has DD of approximately $50 \%$. An extraction procedure was developed in order to characterise it. At the end of the hydrolysis, the reaction mixture was diluted with water 10 times, while the precipitate was dissolved. To remove excess alkali, Amberlite IRC- 
50 cationic exchange resin (Sigma, USA) was used until $\mathrm{pH} 10$ in order to prevent the sorption of chitosan as it is higher than the isoelectric point of glucosamine. Then the alkali residues were removed by dialysis in Spectra/Por Dialysis Tubular Membrane MWCO: 3,500 (Spectrum Laboratories Inc., USA) and lyophilised.

Low molecular weight chitosan was obtained when chitin was treated with $50 \%(w / v) ~ \mathrm{NaOH}$, which is soluble in a wide $\mathrm{pH}$ range. According to HPLC data, two peaks were present in the sample before dialysis: the first corresponds to $\mathrm{M}_{\mathrm{w}}$ of approximately $15 \mathrm{kDa}$, and PI of 1.5, and the second $-\mathrm{M}_{\mathrm{w}} \sim 370 \mathrm{Da}$ and PI 1.1, which accounts for a dimer. According to the chromatogram, the majority of the low molecular weight fraction was removed after dialysis, which depends on the impurities present (protein, ash, phosphate ions). To prove the assumption, amorphous forms of chitin were obtained from crab chitin (Bioprogress LLC, Russia) and shrimp chitin (Sigma, USA), free from these impurities, by dissolving in concentrated phosphoric or hydrochloric acids. The chitins obtained were hydrolysed in $50 \%(\mathrm{w} / \mathrm{v}) \mathrm{NaOH}$. The resulting hydrolysates were also characterised using HPLC, and DD was determined by conductometric titration and ${ }^{1} \mathrm{H}$ NMR. DD was in the range of $42-47 \%$, which is consistent with the accuracy of the methods used.

It was shown that the source of chitin and the acid used do not affect the characteristics of the end product. Thus, it can be suggested that chitin hydrolysis during deacetylation reaction is determined by its amorphous state, i.e. lack of order in its structure.

Table 1. Elemental analysis data of amorphous chitin from H. illucens.

\begin{tabular}{|l|l|l|l|l|}
\hline Samples & \% C & \%H & \% N & \%P \\
\hline Theoretical & 46.38 & 6.28 & 6.76 & 1.93 \\
\hline Experimental & 41.84 & 6.74 & 5.96 & 1.67 \\
\hline
\end{tabular}

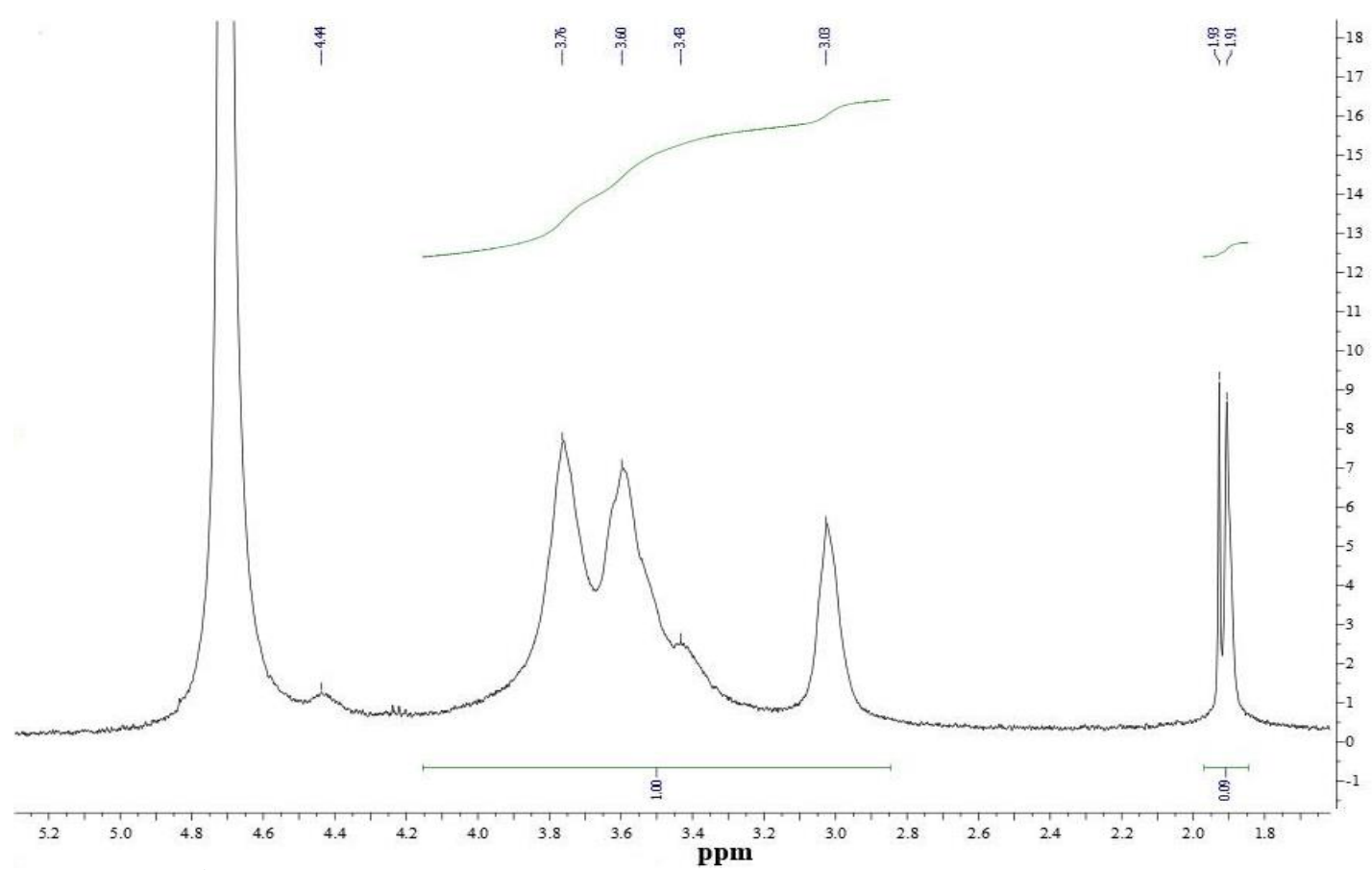

Fig. 1. ${ }^{1} \mathrm{H}$ NMR spectrum of crystalline chitosan obtained from Hermetia illucens larvae. 


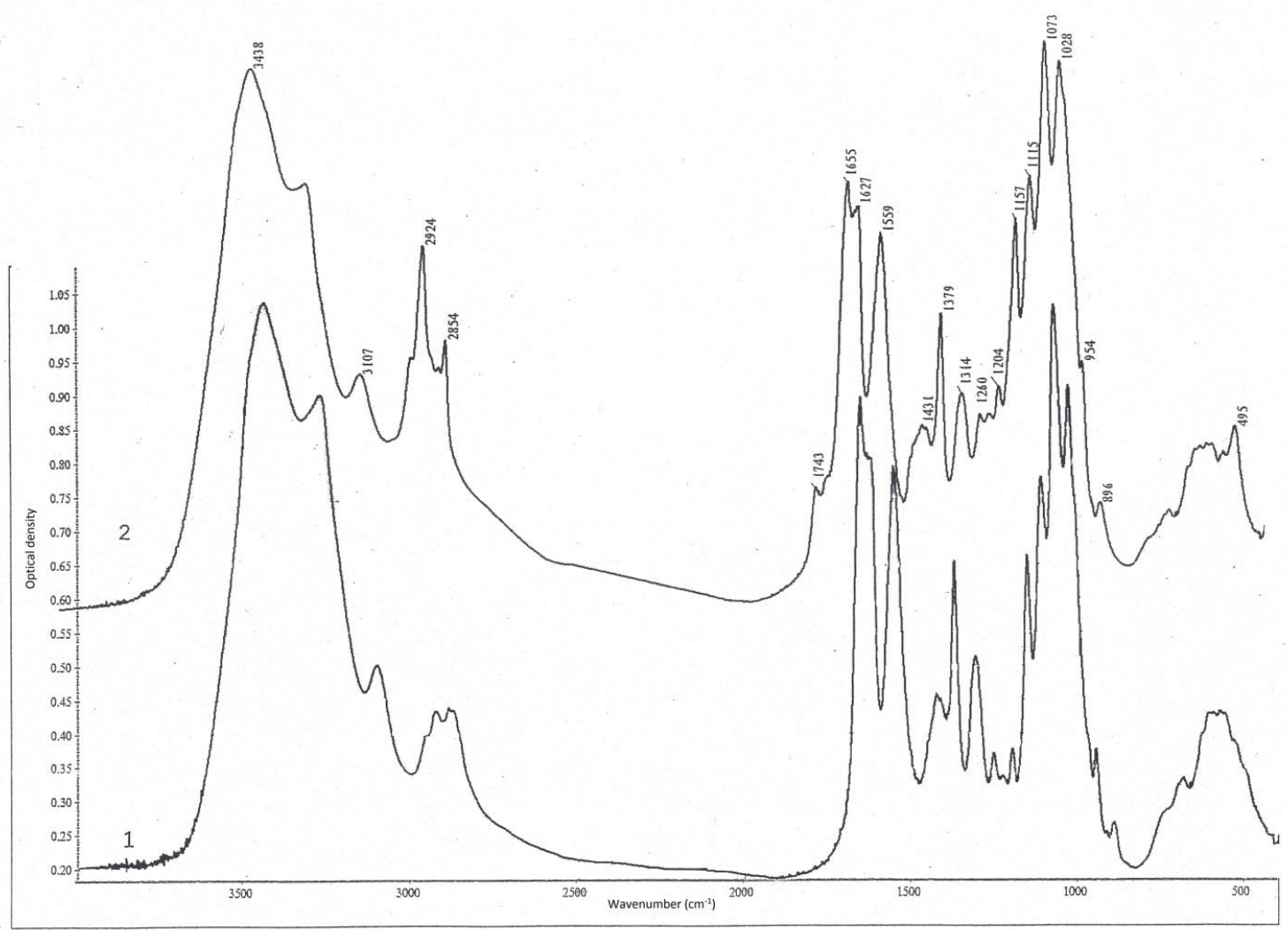

Fig. 2. FT-IR spectra: 1 - reprecipitated amorphous crab chitin, 2 - amorphous chitin extracted from $H$. illucens larvae.

\section{Conclusion}

Two different approaches, one of which included a new extraction treatment, were used to obtain chitin and chitosan from Hermetia illucens larvae. These biopolymers were characterised by elemental analysis, FTIR, ${ }^{1} \mathrm{H}$ NMR and HPLC. Chitin extracted by new method using phosphoric acid was highly amorphous. It was shown that amorphous chitin is destroyed if it is deacetylated. The results confirmed that Hermetia illucens has a potential as an alternative source of chitin and chitosan production for biotechnological, biomedical, and cosmetic applications. Further studies on Hermetia illucens would help to better characterise the chitin properties of this insect species.

\section{Conflict Of Interest}

The authors declare no competing financial interest.

\section{Acknowledgements}

The present research was financially supported by RSF grant 16-14-00046 and Entoprotech LLC.

\section{References}

1. Caligiani, A., A. Marseglia, G. Leni, S. Baldassarre, L. Maistrello, A. Dossena, S. Sforza. (2018). "Composition of black soldier fly prepupae and systematic approaches for extraction and fractionation of proteins, lipids and chitin". Food Research International. 105: 812-820.
2. Croisier, F. and C. Jérôme. (2013). "Chitosan-based biomaterials for tissue engineering”. European Polymer Journal. 49: 780-792.

3. Hirai, A., H. Odani, A. Nakajima. (1991). "Determination of degree of deacetylation of chitosan by $1 \mathrm{H}$ NMR spectroscopy". Polymer Bulletin. 26: 87-94.

4. Kaya, M., S. Erdogan, A. Mol, T. Baran. (2015). "Comparison of chitin structures isolated from seven Orthoptera species". International Journal of Biological Macromolecules. 72: 797-805.

5. Kaya, M., K. Sofi, I. Sargin, M. Mujtaba. (2016). "Changes in physicochemical properties of chitin at developmental stages (larvae, pupa and adult) of Vespa crabro (wasp)". Carbohydrate Polymers. 145: 64-70.

6. Khayrova, A.S., S.A. Lopatin, O.A. Sinitsyna, A.P. Sinitsyn, V.P. Varlamov. (2018). "Obtaining chitin from the black soldier fly Hermetia illucens by direct extraction". Proceeding of the RAS Ufa Scientific Centre. 3(2): 84-88.

7. Knidri, H. E., R. Belaabed, A. Addaou, A. Laajeb, A Lahsini. (2018). "Extraction, chemical modification and characterization of chitin and chitosan". International Journal of Biological Macromolecules. 120: 1181-1189.

8. Kumari, S. and P.K. Rath. (2014). "Extraction and characterization of chitin and chitosan from (Labeo rohita) fish scales". Procedia Materials Science. 6: 482-489.

9. Lopatin, S.A., M.S. Derbeneva, S.N. Kulikov, V.P. Varlamov, O.A. Shpigun. (2009). "Fractionation of chitosan by ultrafiltration". Journal of Analytical Chemistry. 64: 64851.

10. Lopatin, S.A., A.S. Khayrova, V.P. Varlamov, I.V. Sokolov. (2019). The method of obtaining chitin from the larvae of the black soldier fly Hermetia illucens. Russian patent No. 2680691.

11. Luo, Q., Y. Wang, Q. Han, L. Ji, H. Zhang, Z. Fei, Y. Wang. (2019). "Comparison of the physicochemical, rheological, 
and morphologic properties of chitosan from four insects". Carbohydrate Polymers. 209: 266-275.

12. Lyalina, T., A. Zubareva, S. Lopatin, V. Zubov, S. Sizova, E. Svirshchevskaya. (2017). "Correlation Analysis of Chitosan Physicochemical Parameters Determined by Different Methods". Organic and Medicinal Chemistry International Journal. 1(3): 555-562.

13. Mertenat, A., S. Diener, C. Zurbrügg. (2019). "Black Soldier Fly biowaste treatment - Assessment of global warming potential". Waste Management. 84: 173-181.

14. Puvvada, Y. S., S. Vankayalapati, S. Sukhavasi. (2012). "Extraction of chitin from chitosan from exoskeleton of shrimp for application in the pharmaceutical industry". International Current Pharmaceutical Journal. 1: 258-263.

15. Soon, C.Y., Y.B. Tee, C.H. Tan, A.T. Rosnita, A. Khalina. (2018). "Extraction and physicochemical characterization of chitin and chitosan from Zophobas morio larvae in varying sodium hydroxide concentration". International Journal of Biological Macromolecules. 108: 135-142.

16. Taylor, I., A.G. Hovard. (1993). "Measurement of primary amine groups on surface-modified silica and their role in metal binding". Analytica Chimica Acta. 271(1): 77-82.

17. Wasko, A., P. Bulak, M. Polak-Berecka, K. Nowak, C. Polakowski, A. Bieganowski. (2016). "The first report of the physicochemical structure of chitin isolated from Hermetia illucens". International Journal of Biological Macromolecules. 92: 316-320.

18. Younes, A. and M. Rinaudo. (2015). "Chitin and chitosan preparation from marine sources. Structure, properties and applications". Marine drugs. 13(3): 1133-1174. 